\title{
Chapter 12 \\ Integrating Scrum With Other Design Approaches to Support Student Innovation Projects
}

\author{
David Parsons \\ https://orcid.org/0000-0002-9815-036X \\ The Mind Lab, New Zealand \\ Kathryn MacCallum \\ (iD) https://orcid.org/0000-0003-3844-7628 \\ University of Canterbury, New Zealand \\ Hayley Sparks \\ (D) https://orcid.org/0000-0002-6685-7280 \\ The Mind Lab, New Zealand
}

\begin{abstract}
Students who are innovating in a project-based context need appropriate frameworks to support applied research that is easily understandable, flexible to different contexts, and appropriate to their needs. Such support is particularly important when the research involves the development of a technology-related artifact, where students need empirical methods for the design and evaluation of that artifact, in addition to guidance in meeting the academic requirements of their courses. This chapter describes a Scrumbased approach for supporting innovations in learning contexts, extending previous proposals in the literature. The context of the research is two academic programs where students undertake innovative technology-based research projects. The new research model is designed to provide a better supporting framework to assist them to effectively manage their projects by integrating the adaptive cycles and ceremonies of the Scrum agile method with complementary concepts and phases from Design Thinking, Design Science, and Design-Based Research.
\end{abstract}


Integrating Scrum With Other Design Approaches to Support Student Innovation Projects

\section{INTRODUCTION}

For emerging researchers, an understanding of research methods, paradigms and approaches is still developing. Students working in technology innovation are often coming from either the initial stages of higher education or the professional world, where the focus has been on developing artifacts. When translated into an educational context, artifacts are created by students as an outcome of a course of instruction and therefore are similar to the concept of products, which are the outcome of a Scrum process. In an agile software development context, the key outcome is working software (Beck et al., 2001), but in an educational context the set of artifacts is broader, and may include a range of outputs used for assessment, such as designs, reports, strategies, plans etc. Students undertaking this type of study have often not been exposed to the concept and application of research and often have little understanding of how research and product development fit together. They therefore struggle with framing their research, and understanding where the development of the artifact fits within the research process.

The various strands of design research (in both information systems and education) have been developed to help link artifact development with an empirical process, with a focus on rigor in both the development of the artifact and its evaluation. We use the broad term "design research" here to include both design science (also known as design science research) and design-based research, as described later. However, for emerging researchers, the link is not always clear between the development methodology and the research contribution. Design research methods can work well in more substantial research projects (such as doctoral projects) which are significantly longer and can support multiple full-cycle iterative designs, but are not ideal for the scale and learning focus of smaller student projects that may only take one semester.

The focus of this chapter is to outline the development of a guiding framework for emerging researchers so that they can balance the relevance of product development with the rigor of research within the constraints of short, learning-focused projects. This framework is based on iterative Scrum cycles supported by a Design Thinking phase and some complementary techniques drawn from design research. The development of this framework has arisen from the need to provide students with a process that would guide them when undertaking a research project focused on artifact development. Two different contexts of student research have been used as the motivation and testing ground for the ideas that have been incorporated into the framework presented in this chapter.

\section{Background Context}

The background context of this study is two higher education programs in different institutions that focus on technology innovation. In both cases, students work on substantial projects that are based on new and disruptive technologies, so their learning is constructionist in nature. In one context, the students are postgraduates with a diverse background, many with industrial experience. In the other context, the students are undergraduates working with industry clients to develop systems. In both cases, the students are focused on the creation of new technology products and typically have little concept of research when they enroll on their programs.

Context 1 is a private graduate school which offers a Master's program in technological futures. This program is focused on an applied project. The students are required to develop an innovative product (artifact) situated in a real-world context using emerging technologies and appropriate research methods. The students within this Master's are typically mature students who have come from an industry back- 
Integrating Scrum With Other Design Approaches to Support Student Innovation Projects

ground, with many wanting to undertake a program that will help them start a new venture or scale an existing one focused on new and emerging digital technologies. Since this program was developed for professionals, helping them situate research alongside the development of artifacts was needed. Many of these students had finished their undergraduate programs many years previously, or had entered postgraduate study through professional pathways, and had little research and academic background. Therefore, tying in industry concepts with a research method that was focused on strengthening their existing knowledge was necessary.

Context 2 is a regional polytechnic offering mostly vocational programs. The program considered here is an undergraduate degree in computing. Within that program is a pathway for students developing an artifact which is industry-focused, with a specific industry client. The challenge for these students is to ensure that while they are focusing on creating a specific product for an industry client, they are also meeting the academic requirements for their qualification, to ensure that they are both research-informed and producing material that is suitable for academic assessment.

This chapter outlines a framework which marries innovations with reflective knowledge development and dissemination, suitable for student research projects. The focus is to develop a process that can be easily followed, and which adopts robust and systematic methods for the development and evaluation of innovative products. This can better support student project work by recommending a specific research process suitable for innovative learning. By drawing together ideas from agile methods, Design Thinking, and design research the proposed process could be followed to guide students developing a practical project framed by research.

The following sections begin by introducing some observations around the common challenges faced by research students from less academic backgrounds, and what is needed from a supporting framework that can assist them in successfully managing their innovation projects. This is followed by a discussion about how design research, Scrum and Design Thinking might each contribute to a new framework, while acknowledging that none of these approaches was intended for students individually undertaking course-based research in limited timeframes and therefore cannot be adopted uncritically. The next section develops some theoretical ideas around how different aspects of the various approaches being discussed have been combined in previous research, and how their synergies may be interpreted in the context of this study. The chapter then describes the framework that has been developed from these various theoretical strands to help support students in implementing their projects, which is intended to be used as part of a student guide to research in innovation projects. The chapter concludes with some reflections on the current status of the framework and outlines future work.

\section{ISSUES IN INNOVATIVE STUDENT RESEARCH PROJECTS}

In observing students working through their projects the researchers have, despite project and student diversity, identified several common factors where better support is required.

Time management is unsurprisingly essential. Students need a framework to structure their research timelines and milestones and manage multiple workflows at the same time to ensure timely completion, while integrating planning as a continuous process (Peters et al., 2012). However, many students try to start at the solution and do not understand the importance of process, or of having an iterative approach and openness to exploring a range of different approaches / processes. 
Students in the two contexts being investigated often work on projects independently but usually within real contexts and need to factor in engagement with stakeholders and/or experts when required. In addition to managing this time, students need support in how they engage with these stakeholders. In most cases, these stakeholders are product end-users, where engagement is required to ensure that the product meets their needs. However, in cases where projects are embedded in an industry with a specific client, students also need to balance clients' expectations and to ensure that projects are suitably scoped to meet the needs of the client as well as their own learning outcomes. In these cases, students are often supported by the supervisor of the program to ensure that managing scope and changes in requirements can be balanced to still ensure that a successful outcome can still be reached, even if the outcome is not the final version but just a proof concept or minimum viable product. Since a core concept of agile methods is that scope has to be traded off when new requirements arise, academics need to support students by allowing for flexible assessment criteria that are able embrace change in an agile manner. This requires an awareness of the different metrics needed for student projects and aspects of continuous assessment (Bai et al., 2018).

Students also need to understand that the main required output of a research process in an academic context may not necessarily be the product or technological artifact they are basing their research around but could be a theoretical contribution disseminated as a research article or whitepaper. They struggle with integrating research methodology into a product development context, often focusing on the development of the artifact and developing little understanding of the empirical rigor and robust data collection needed in research.

A flexible and adaptive process is important given the diversity of project foci and possible outputs, and because plans often change considerably. Students who are unable to adapt run out of time, particularly if they are working at the same time as studying. They need to be flexible about potentially having multiple different outcomes that may or may not all become final products or outputs depending on how other aspects of the process play out.

Students also need to be able to begin the substantive part of the process at different points depending on the project (idea, context, level of existing background knowledge). Some projects can be related to well-understood challenges and opportunities and therefore less background research is required, while others might be related to less well-understood challenges and opportunities and therefore more initial research is required. Similarly, they need to be able to restart the process or begin again at a particular point in the process in case of pivots in projects. Although an adaptive and iterative process is required, time constraints limit the number of iterations that can be accommodated.

The context of student research based on practical projects that create useful artefacts is typically addressed by the field of Design Science Research within the Information Systems discipline. The generalized stages within a design science research approach are the identification of a relevant problem, the development of an artifact that addresses the problem, evaluation of the artifact, articulation of its value, and an explanation of the implications (March \& Storey, 2008). However, there are many different interpretations in the literature of how design science should be implemented, and many are highly academic and unsuited to industry focused courses. The researchers' experience with students working on applied projects has suggested that design science research has much to offer to academic study but does not help students to develop contemporary skills in an industry that is increasingly based on agile processes.

As an alternative approach, this chapter proposes that Scrum provides a suitably adaptive and flexible framework to address some of the problems outlined above by supporting iterative feedback loops 
with meaningful milestones without over-emphasizing the various philosophical intricacies of different design science approaches. However, there remain some issues that Scrum alone does not clearly address, such as assisting student engagement with stakeholders and the evaluation of multiple options. In these areas, Design Thinking has shown promise. Design thinking is generally defined as an analytic and creative process that engages a person in opportunities to experiment, create and prototype models, gather feedback, and redesign (Razzouk \& Shute, 2012). We believe that it provides a strong complement to a Scrum-based research process, as outlined later in this chapter. In addition, we recognize that there are elements of design science research might be integrated with these more industry-focused approaches to ensure that academic rigor is retained in an educational context. In addition, the field of Design-Based Research, which is similar to design science but focused on education, is also considered for possible contributions to a revised model of what a more agile student project process might look like. The current state of progress of developing a Scrum-based design approach for student innovation projects that integrates concepts from Design Thinking, Design Science and Design-Based Research is described in this chapter.

\section{DESIGN SCIENCE RESEARCH IN INFORMATION SYSTEMS AND EDUCATION}

The intention of adopting the approaches embedded within design science (research) is that the creation of a technology artifact can be managed through a rigorous and repeatable research process that creates not only an artifact relevant to its context but also a contribution to the knowledge base. Design science was initially rooted in technology products, but educators saw the value of a design science of education to enable the introduction of new learning technologies. This work has grown into the field of design-based research, which focuses on the learning sciences. There is, however, no single model for how such research can be undertaken, with multiple approaches to both design science and designbased research, with many different emphases on iterative step sequences and adaptation to context, as outlined in the following sections.

\section{Design Science Research Frameworks}

Design science research in Information Systems focuses on the design and creation of technology artifacts in an iterative process. There are several design science frameworks, each with their own particular structures and emphases. One of the earliest was the Design Cycle by Takeda et al. (1997). They described an iterative logical process to assist in designing outcomes that cannot be fully known upfront and introduced abduction and deduction phases to acknowledge this challenge.

The Design Cycle forms the basis (along with other early models) of Vaishnavi and Kuechler's (2011) Design Science Research Cycle (developed from work first published online in 2004). The first two steps in their process ("awareness of problem" and "suggestion") establish a project as research, followed by deductive stages of development, evaluation, and conclusion. The cycle is explicit about there being multiple iteration points - at any stage, the cycle may return to further developing awareness of the problem. The circumscription process that takes place during the main body of the cycle (prior to reflection) emphasizes the way that specific acts of construction generate understanding that is contextualized to that research process, so theory cannot predict validity in advance. 
Design Science in Information Systems Research (Hevner et al., 2004) was developed around the same time as the Design Science Research Cycle but provides a somewhat different set of key concerns. It emphasizes the necessary balance between relevance and rigor, and the importance of research projects adding not only to the knowledge base but also to be applied in the appropriate environment of people and organizations. There is an expectation that the creation of an artifact also creates improvements or extensions to theories or methods. Although the model includes a cycle of assessment and refinement, there is no concept of multiple entry or exit points in the process. In summary, this model is more concerned with the broader research contexts and outcomes than the mechanics of the design science research process.

The Design Science Research Methodology for Information Systems Research (Peffers et al., 2007) has a similar approach to Vaishnavi and Kuechler's model of iterating back to the original problem space from various points in the cycle. However, it also includes multiple entry points to the research, and the process iteration concludes with communication. The method goes through a series of iterations with explicit sequential steps: Identify the problem and motivate, define the objectives of the solution, design and development, demonstration, evaluation, and communication. Like Hevner et al. it emphasizes the contribution aspect of the design science research, with "disciplinary knowledge" being the final outcome.

\section{Design-Based Research}

Although design science was initially rooted in technology products, as early as 1992 Collins was proposing a design science of education (commonly referred to now as design-based research) to enable the introduction of new technologies. A key concept was that the innovation being evaluated could be much broader than a single artifact (Collins, 1992).

Kelly (2004) further elaborates on the outcomes or products from design-based research studies. These may be about models of practice, or learning, or the design and use of a new software tool or learning environments. The main message is that design always leads to an artifact, but that artifact could be a non-tactile outcome such as a new theory. Cobb et al. (2003) reinforce this idea that it is a theory-oriented enterprise, where the theories do real work in practical educational contexts. This idea also emphasizes the links to design science by stating that such design experiments are extended (iterative) and interventionist (innovative and design-based).

Van Den Akker et al. (2006) provide a further set of criteria for design-based research, that it should: 1) aim at designing an intervention in the real world; 2) incorporate a cyclic approach of design, evaluation, and revision; 3) focus on understanding and improving interventions; 4) measure the merit of a design by its practicality for users in real contexts, and 5) be based on, and contribute to, theory. Amiel and Reeves (2008) also highlight the need for a systematic approach to producing research that makes a difference, but also suggests the importance of collaborative methods of investigation.

Unlike design science research in information systems, the design-based research community has not developed extensive frameworks for the process. For example, Brown's (1992) model is a simple construct of inputs to engineering a working environment, and subsequent interactions with theory, outputs and dissemination. The most developed model for education design research is probably McKenney and Reeves' (2013) generic model, with an iterative cycle of analysis / exploration, design / construction, evaluation / reflection and intervention / understanding. The iterative model includes returning to any previous stage from intervention / understanding. 
Integrating Scrum With Other Design Approaches to Support Student Innovation Projects

Despite the broad variations in all these examples, from design science and design-based research, there are some common themes that emerge. All of these models are iterative, though there are some variations in where and when these iterations might take flight. They all take into account that the research process goes through different phases and that outputs of the process may be theoretical as well as based on creating an artifact. The overall process is on focusing initial uncertainty through adaptive cycles of learning and a final phrase that focuses on the communication of outcomes. One model, at least, also emphasizes collaboration.

In the context described in this chapter, the aim is to assist student-researchers to manage very diverse innovation projects that may emphasize either product or theory by providing an explicit process that acknowledges the common threads of design science and design-based research while also ensuring that these projects meet the program schedule. A model is needed that is suitably lightweight for small scale, short term student projects, though one that could be expanded, if necessary, to be applied for a longer time scale. The published models discussed above are essentially too focused on process rigor, when many students need to produce output relevance. With this in mind, agile methods (Scrum in particular) have been explored as an alternative model for such projects as being industry relevant, adaptive, simply explained and easy to follow.

\section{AGILE METHODS AND SCRUM}

In the 1980s, innovative product companies were shifting from linear to integrated approaches that stimulated new kinds of learning and thinking in breadth (Takeuchi \& Nonaka, 1986). By the late 1990s, software development methods were becoming increasingly integrated and iterative by leveraging new technologies and a greater understanding of the development process to embrace change. In 2001, the developers of these new ways of thinking got together to create the Manifesto for Agile Software Development (Beck et al., 2001), which outlined the key values and principles of this approach to building applications. Since then, agile methods have become the predominant global approach to the building of software.

The idea that methods developed from the processes and techniques of the software industry, particularly agile thinking, can be applied to teaching and learning in other domains has become increasingly popular (Parsons \& MacCallum, 2019). Software developers were the first to articulate the properties of effective team design, but agile approaches are not particularly tied to software development and can easily be applied to other domains (Cockburn, 2008). Agile approaches, which are founded on continuous learning and improvement, supported by regular reflection and collaboration, seem to hold much promise for education.

The most popular agile method, and the one most focused on within a project management context (as opposed to software engineering), is Scrum (Schwaber \& Sutherland, 2017). The concept of Scrum comes from research on innovative product development companies (Takeuchi \& Nonaka, 1986) where traditional methods of development were characterized as being like a relay race, a siloed process where each step is separated from the next, while new approaches were more team-based with everyone moving forward together - hence the analogy with the team game of rugby, from which the term "Scrum" comes. In this sense, Scrum is ideal for collaborative student projects but can also be a suitable framework for individual projects, since all projects have to involve stakeholders. 
The Scrum framework emphasizes transparency, inspection, and adaptation, which its authors claim makes it an empirical process, and can provide useful guidance for applied educational research projects. The Scrum process of creating a backlog of items that feeds into multiple timeboxed sprints, each producing a meaningful incremental product and followed by a review and retrospective, can be an effective way of keeping research projects on track. A Scrum-based approach has been applied to some programs in the context under discussion to support iterative progress and reflective practice for the development of learning artifacts (products). However, experience suggests that Scrum alone does not provide suitable scaffolding for the early phases of research, nor take account of the nature of academic outputs.

The main problem with using Scrum as a framework for student research is that the Scrum framework was designed with the needs of the software development community in mind. For software projects, the Scrum guide (Schwaber \& Sutherland, 2017) assumes that there is a product owner who is able to bring requirements from the customer into the team. It does not provide details on how this original backlog building process takes place since it focuses on the development cycle, not on the gathering of requirements. At the other end of a project, the output from a Scrum software development process is simply a software product to be delivered to the customer. As we have seen from design research frameworks, one of the important considerations is how the output of a project is represented, given that this output may not be any kind of product but could perhaps just be theoretical. Therefore, Scrum is a valid approach to the central series of iterations of a project, where the work is actually done, but students need more structure to the development of an initial backlog for a Scrum-style process of sprints to begin. They also need more support in the process of generating a final output and disseminating it to the relevant stakeholders, which might be, for example, examiners or publishers as well as clients

\section{DESIGN THINKING}

Given the issue of how to create a suitable project backlog for a Scrum style process, any series of sprints needs to be preceded by a suitably investigative and creative way to develop a research-focused backlog. One approach that can be used for this purpose is Design Thinking, "an inventive process, through which problems are identified, solutions proposed and produced, and the results evaluated...Succinctly stated, it is purposeful, problem solving thought and action." (Norman, 2001).

As innovative product companies started shifting from linear to integrated approaches in the 1980s, which later led to the Agile movement, Design Thinking also arose. In one of the earliest books on the topic by Peter Rowe, published in 1987, Design Thinking originated within the industrial design and engineering sector (Kimbell, 2011). Design Thinking sprang from the need to develop a process that would help reconceptualize and comprehend problems that were otherwise complex or ill-defined. A significant part of the problem-solving process in Design Thinking involves the ability to synthesize knowledge from various sources as well as take the design of a solution from a user-centered orientation (Koh et al., 2015). Due to this user-centered nature, Design Thinking has been extremely popular within education contexts, as it provides a structure for students to creatively solve the complex problem through the application of ideation and prototyping (Melles et al., 2015). Design Thinking has also been adopted within a formal research context, with some researchers claiming that its adoption within Action Research can provide stronger outcomes (Romme, 2004).

Design Thinking has no single model, and each model tends to vary quite significantly in the terms that it uses, but the model used in the context discussed in this chapter is a customized version of the 
Stanford d.school model of empathize, define, ideate, prototype and test (Stanford, 2019). This adapted model of design thinking adds "reflect" and "iterate" stages to the end of the d.school design thinking process to make it more compatible with an academic research context and to more clearly integrate it with the iterative nature of Scrum. Unlike most of the models looked at so far in this chapter, Design Thinking puts a strong emphasis on upfront discovery and ideation based on empathizing with the customer. This raises important questions about the definition of "customer" in an academic student project, which broadens to encompass a range of stakeholders beyond the normal design context, including supervisors, examiners, and publishers.

\section{INTEGRATING PROCESS MODELS}

Given that this discussion has drawn on multiple process models, it is important to acknowledge that some of these models have previously been integrated by others. This study is not the first to suggest that agile approaches can be combined with the concepts of design science / design research. For example, Keijzer-Broers and de Reuver (2016) describe developing a health and well-being platform using an approach that combines the distinct stages of a design science process with the concept of a series of agile sprints. This does capture what is perhaps the key difference between an agile process and design research, which is that design science research recognizes that there are explicit phases in the overall process, whereas agile methods do not make explicit distinctions between the types of activity taking place in the sprints, with the exception perhaps of "sprint zero" which initializes the process. The danger with this interpretation is that it removes the iterative revisiting elements from design research models that recognize the specific tasks within each stage, and also the broader flexibility of agile methods that do not dictate what happens in each sprint, and leans more towards a waterfall style process (Royce, 1970).

Conboy et al. (2015) have proposed the Agile Design Science Research Methodology. Based on Peffers et al. (2007). The main feature of this model is that it loses nothing of the existing design science research structures and process. However, this also means that the additional contribution is limited to some elaboration of each stage and an initial "problem backlog" stage. The additional "hardening sprint" is focused on rigor rather than any specific enhancements to the model, so does not provide any fundamental rethinking of design research from an agile perspective. These issues suggest that attempting to add agile methods to a design research process is ineffective because of the sequential structures of these processes, which have more in common with pre-agile iterative frameworks. A better approach may be to wrap an agile Scrum process within additional features from other design processes, which could preserve the adaptive nature of Scrum while bolstering it with a theoretical foundation and outcomes.

Design Thinking and agile methods have also been integrated by some authors, for example, Gurusamy, et al. (2016) map requirements, design and evaluation in agile sprints to different parts of the Design Thinking cycle, while IBM (2018) integrate the discovery aspect of Design Thinking with the delivery aspect of agile methods. This other work suggests that there is a useful role for Design Thinking in agile processes, specifically as a necessary precursor to building a project backlog. 


\section{DEVELOPING AN INTEGRATED SCRUM-BASED RESEARCH FRAMEWORK}

This section provides a brief comparison of the main process models previously introduced, then presents how these can be integrated. This integrated process draws from multiple sources to address the particular requirements of the programs for which it is designed. This process is described as a Scrum-based research framework since it is primarily based on the artifacts and ceremonies of Scrum. However, it also draws on some ideas from design research and elements of Design Thinking. Table 1 summarizes the key process stages and notable features of the main frameworks that have been considered in this chapter. These include the main concepts from these different sources that have been carried forward into the proposed process model that is shown in Figure 1.

Table 1. Concepts from various models

\begin{tabular}{|c|c|c|}
\hline Model & Key Process Stages & Notable Features \\
\hline $\begin{array}{l}\text { Design Science Research Cycle } \\
\text { (Vaishnavi \& Kuechler, 2011) }\end{array}$ & $\begin{array}{l}\text { Awareness - suggestion - development - } \\
\text { evaluation - reflection }\end{array}$ & $\begin{array}{l}\text { Multiple iteration points, circumscription to } \\
\text { context - begins with awareness }\end{array}$ \\
\hline $\begin{array}{l}\text { Design Science in Information Systems } \\
\text { Research } \\
\text { (Hevner et al., 2004) }\end{array}$ & $\begin{array}{l}\text { Environment \& knowledge base - } \\
\text { construction - assess \& refine - evaluation } \\
\text { - contribution }\end{array}$ & $\begin{array}{l}\text { Focus on contexts and contribution rather } \\
\text { than process detail - emphasizes the } \\
\text { environment and knowledge base }\end{array}$ \\
\hline $\begin{array}{l}\text { Design Science Research Methodology } \\
\text { for Information Systems Research } \\
\text { (Peffers et al., 2007) }\end{array}$ & $\begin{array}{l}\text { Identify problem - define objectives - design } \\
\& \text { develop - demonstrate - evaluate - } \\
\text { communicate }\end{array}$ & $\begin{array}{l}\text { Multiple entry points and emphasis on } \\
\text { communication }\end{array}$ \\
\hline $\begin{array}{l}\text { Design Science of Education } \\
\text { (Collins, 1992). }\end{array}$ & $\begin{array}{l}\text { Multiple innovations - objective evaluation } \\
\text { - prioritize candidate technologies - multiple } \\
\text { expertise - systematic variation - flexible } \\
\text { design revision - multiple evaluations. }\end{array}$ & $\begin{array}{l}\text { Introduction of new technologies. } \\
\text { Innovation could be much broader than a } \\
\text { single artifact }\end{array}$ \\
\hline $\begin{array}{l}\text { Design Experiments (Brown, 1992; Cobb } \\
\text { et al., 2003) }\end{array}$ & $\begin{array}{l}\text { Inputs - working environment - contribution } \\
\text { to theory - dissemination }\end{array}$ & Focus on contribution and dissemination \\
\hline $\begin{array}{l}\text { Generic Model for Educational Design } \\
\text { Research } \\
\text { (McKenney \& Reeves, 2013) }\end{array}$ & $\begin{array}{l}\text { Analysis/exploration - design/construction } \\
\text { - evaluation/reflection - intervention/ } \\
\text { understanding }\end{array}$ & $\begin{array}{l}\text { Potential iterations back from final stage to } \\
\text { any previous stage }\end{array}$ \\
\hline $\begin{array}{l}\text { Scrum } \\
\text { (Schwaber \& Sutherland, 2017). }\end{array}$ & $\begin{array}{l}\text { Backlog - sprints - review - retrospective } \\
\text { Multiple timeboxed sprints }\end{array}$ & $\begin{array}{l}\text { Sprints, empiricism, ceremonies and } \\
\text { artifacts }\end{array}$ \\
\hline Design Thinking (Stanford, 2019) & $\begin{array}{l}\text { Empathize - define - ideate - prototype - test - } \\
\text { reflect - iterate }\end{array}$ & $\begin{array}{l}\text { Ideation of multiple options upfront, } \\
\text { prototypes and iteration }\end{array}$ \\
\hline
\end{tabular}

The Scrum-based research framework (Figure 1) is primarily informed by a need to provide a more explicit process framework to research students while maintaining the agile sprint cycles that have proved beneficial thus far. It is also deliberately simple and so does not present a large number of optional pathways.

The main concept is that the series of iterative sprints that comprise the main "Scrum Cycle" phase are pre-scaffolded by a "Pre-Scrum" phase and followed by a "Post Scrum" phase in a structure that draws ideas from the other process models included in Table 1. The following sections step through each of these three phases before summarizing how the whole framework is intended to support iterative development. 
Figure 1. A Scrum-based research framework for innovation-based projects

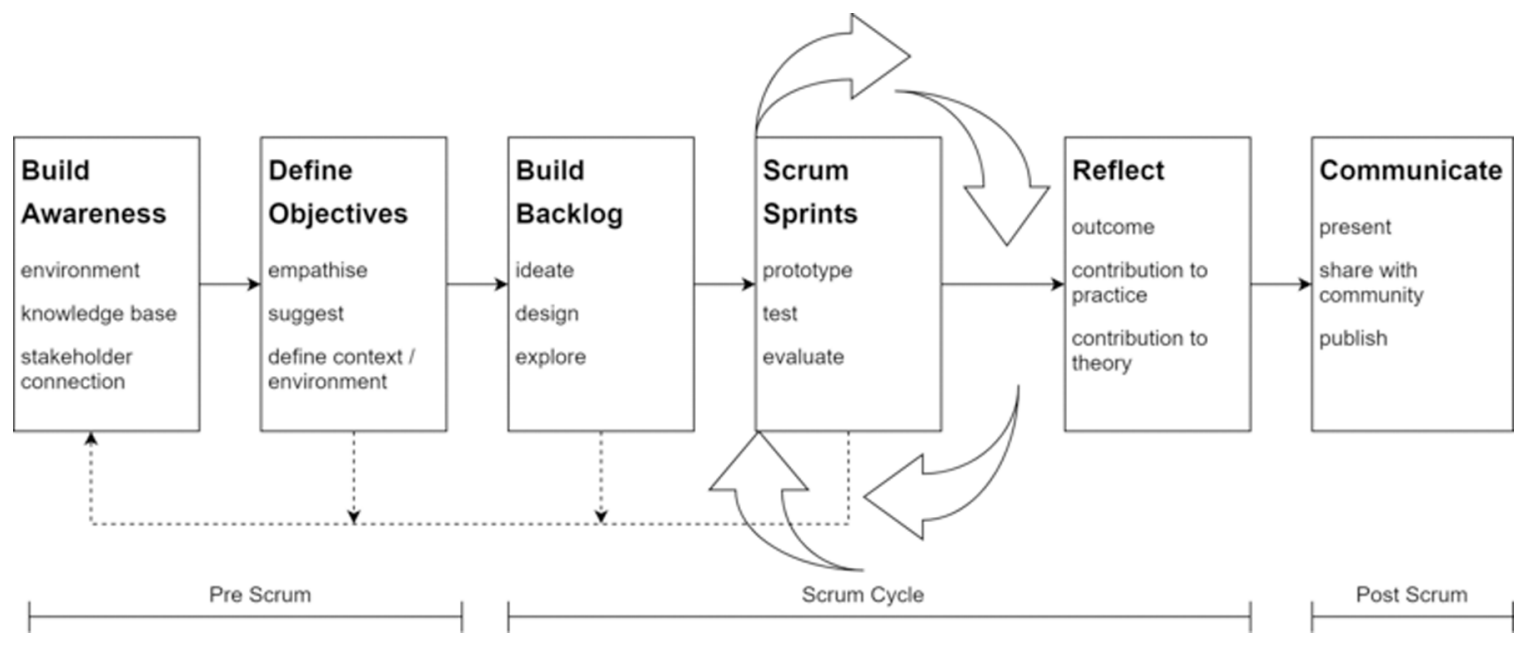

\section{Pre-Scrum Phase}

The first stage of the Pre-Scrum phase is "Build Awareness" (Figure 2) a concept taken from Vaishnavi and Kuechler's Design Science Research Cycle (2011).

Scrum projects tend to bypass the concept of building awareness because they are customer-driven. There is an assumption that the Product Owner brings awareness directly to the team. An initial research phase that focuses on the environment, the knowledge base and connecting with the stakeholders is therefore included. The environment and knowledge base concepts are taken from Design Science in Information Systems Research (Hevner et al., 2004). In an educational context, whether or not students are working for external clients, there is a need to ensure that suitable research is done into the literature as well as any technical information that might be needed. The stakeholder connection is essentially a replacement for the Scrum Product Owner, who normally channels information and requirements from customers and the host organization. In this phase, students need to identify and gain input from clients (if they are building a product), supervisors and other relevant bodies such as ethics committees and impacted communities.

This is followed by a second "Define Objectives" stage, where empathy is built with the stakeholders (a key part of Design Thinking) and suggestions are drawn from the awareness phase. The first part of a Scrum process, building the project backlog that can be used in the Sprints, requires activities driven by the Product Owner. In student research, the student (or student team) essentially becomes the Project Owner. In this role, they need to be able to define a set of objectives that suggest the core research ideas of the project, empathize with their stakeholders, and clarify the boundaries around their research context and environment. The suggestion process, taken from the Design Science Research Cycle (Vaishnavi \& Kuechler, 2011) involves the abduction of research possibilities from the knowledge of the domain gained in the previous awareness building stage. 
Figure 2. The "Pre Scrum" phase of the framework

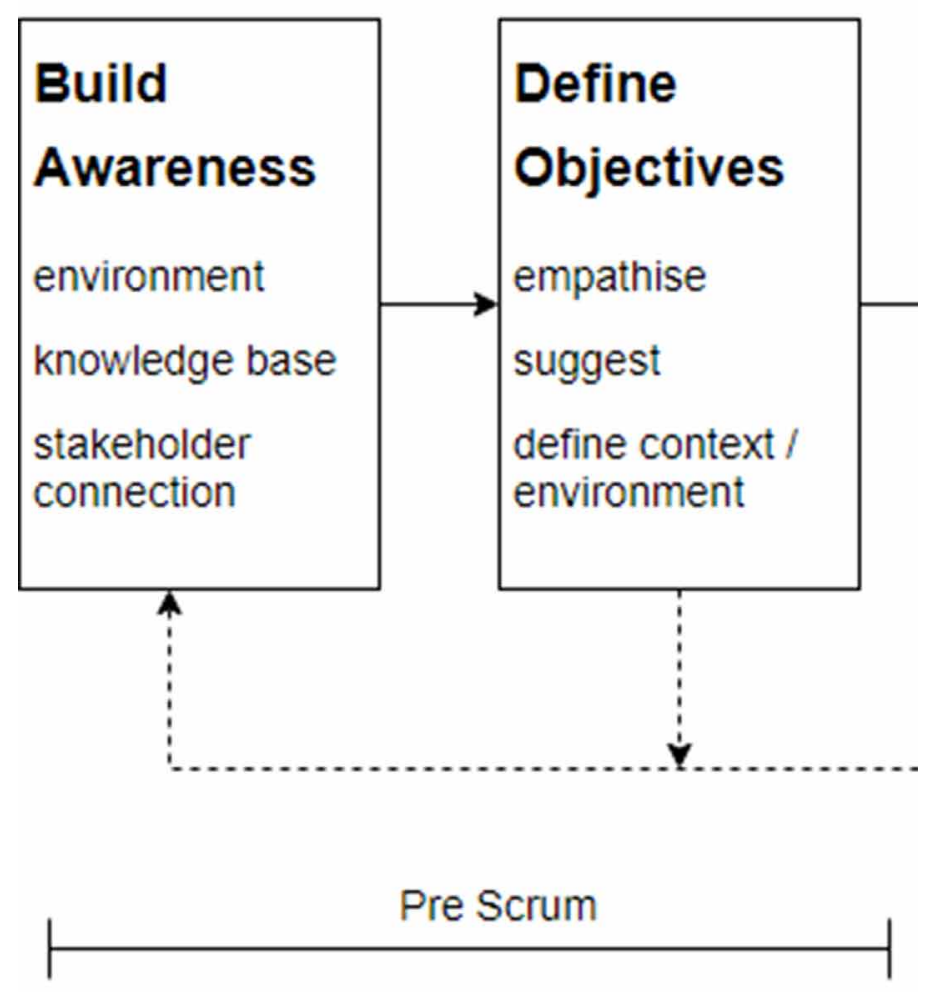

\section{The Scrum Cycle}

At the heart of the proposed research project framework is a "Scrum Cycle" (Figure 3) that embodies the key concepts of creating a project backlog, working through that backlog in a series of timeboxed sprint cycles, and ending with reflection phase (similar to the Scrum review / retrospective).

The first part of the Scrum Cycle, the "Build Backlog" stage, involves the ideation of multiple ideas, which draws concepts from both Design Thinking and Collins' (1992) Design Science of Education, whereby students need to consider multiple aspects of an innovation (multiple technologies, multiple expertise, systematic variation etc.) when scoping their backlog.

"Scrum Sprints" are focused on prototyping, testing and evaluation, in a series of timeboxes that should each contribute a specific increment towards the final project outcome, with the evaluation comprising the usual Scrum ceremonies of Sprint Review (assessing what has been achieved) and Sprint Retrospective (assessing where the Sprint process and practices could be improved). The length of a Sprint depends on the length of the student's program of research, but common Scrum timeboxes of two to four weeks would probably be appropriate for most students. 
Figure 3. The "Scrum Cycle" phase of the framework

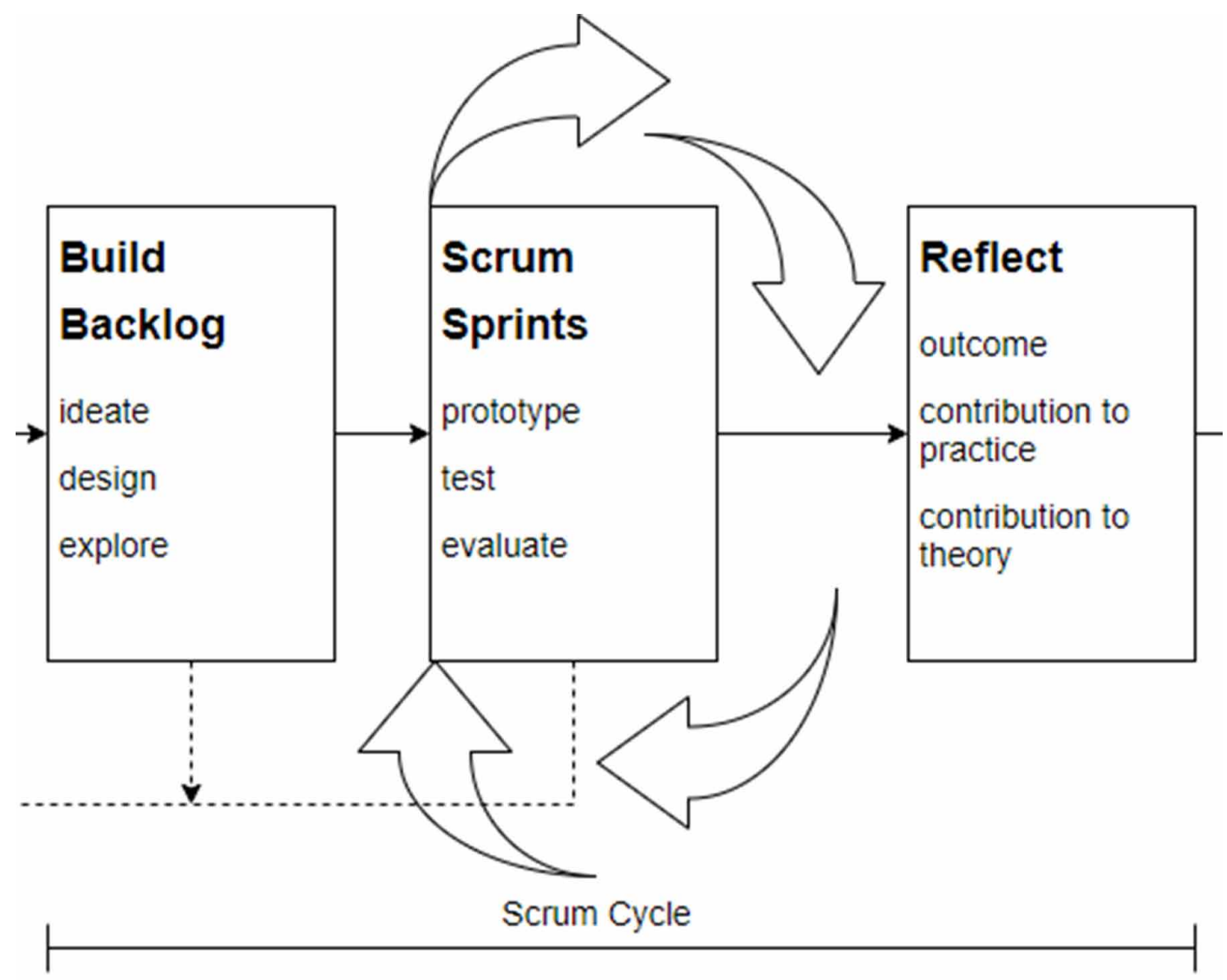

The "Reflect" stage is part of the usual Scrum project review and retrospective but has a focus on implications for theory and practice. From an academic perspective, a review is the achieved contribution of the project and the retrospective is identified as future work.

\section{The Post-Scrum Phase}

Following other academic models, the final "Post Scrum" phase deals with how the outcomes of the work are communicated (Figure 4). This phase acknowledges that a Scrum process in software development ends with the delivery of the product to the customer, but that in an academic context this is only one deliverable of the research process. The value of the communication stage is therefore not the artifact itself but the design principles of the product and the contribution to practice and theory that are embedded in the reflection stage at the end of the Scrum Cycle.

The nature of this communication will vary by there is an assumption that the work will be presented in some way for assessment, but that it should also be appropriately communicated to the community of stakeholders, and potentially also be published in a more widely accessible forum. 
Integrating Scrum With Other Design Approaches to Support Student Innovation Projects

\section{Framework Iterations}

The main iterations within the framework presented here take place in the Scrum Sprints, but students may need to pivot back to any of the precursor stages if major adaptation is required. Although there is a single entry point to the model, the level of work in the first two stages may be minimal in well-defined projects (but it is recommended that they are still addressed).

In the other models explored in this chapter, the concept of iteration is common but the ways in which iteration takes place vary widely. Some models, such as Design Science in Information Systems Research (Hevner et al,, 2004) choose not to discuss how, when or why iteration will take place, but simply assume that some kind of "assess and refine" cycle will be involved. Other models specify explicit exit and entry points for iteration. The Design Science Research Methodology for Information Systems Research (Peffers et al., 2007) identifies iteration points from Evaluation or Communication back to Defining the Objectives or Design and Development. Still others seem to allow for iteration from any one step back through any other, such as the Generic Model for Educational Design Research (McKenney $\&$ Reeves, 2013). Such design decisions are dependent on the focus of the framework, the number and breadth of steps in the framework, the nature of the steps within which or between which iteration may take place, and the logic of iterating between specific steps, depending on their related activities. In the model presented here, there are two layers of possible iteration. One is the standard Scrum iteration of timeboxed Sprints, which takes place in the main Scrum Cycle phase. There is another set of possible integration points prior to this to enable students to redefine and re-populate the backlog in the light of changing requirements or discoveries made during implementation Sprints. In this sense, a Sprint may involve a timeboxed cycle back through the "Build Awareness", "Define Objectives" and "Build Backlog" stages. In addition, the "Build Backlog" stage may iterate back to further building of awareness and objectives definition, and there may also be an iteration back from defining objectives to building awareness. The reason for explicitly including these types of iterations in the model is to give students guidance about when they might need to revisit prior stages in order to ensure that their project remains on track, particularly given the nature of agile methods to be able to embrace change.

\section{USAGE SCENARIOS}

In order to illustrate how this model could be conceptualized within a real-world educational situation, two scenarios are outlined. These scenarios illustrate two different ways in which we believe the framework will better guide research students at the two institutions focused on in this article. As discussed at the beginning of this chapters the two contexts are a Master's program in technological futures and an undergraduate degree in computing.

\section{Scenario 1: Master's Program in Technological Futures}

The first scenario describes the way in which the adoption of this model may assist with the development of innovative technological solutions to address challenges associated with the future of work and changing, complex work environments. Many postgraduate Master's projects have begun with the aim of using emerging and disruptive technology (EDT) in this context, and a range of different outputs have been proposed. These outputs range from a digital technology solution for understanding workplace 
Figure 4. The "Post Scrum" phase of the framework
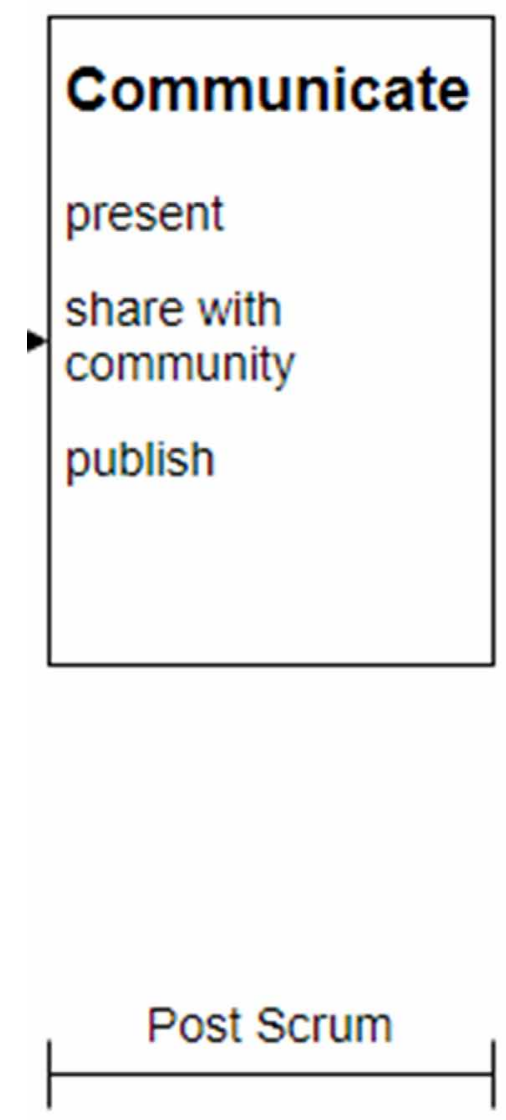

organizational charts, through to new frameworks for businesses to provide more flexible working arrangements and technological solutions to improving professional development. These students spend a significant amount of time developing a project proposal, however, guiding students through the use of robust and systematic research processes to validate the opportunity they are pursuing, and test assumptions that underlie the project can be challenging. For example, encouraging students to test the assumption that current organizational charts are not effective, and that EDT can be used in this space requires reading a lot of research from a range of different disciplines. This challenge is particularly apparent with students beginning the program with a set idea of the artifact they want to produce and are then afraid to test their assumption and find out that there is already a product in the market similar to what they were planning to develop. The need to build a bank of evidence and research (from both academic and grey literature) to help them validate the idea, and assess its feasibility, to essentially become experts on their idea can be difficult, especially if the problem is not well defined, and when research of this nature is not something they have experience doing. It is often commented by students who come from professional backgrounds that they are used to being told what the problem is that they need to address and are provided with research that confirms the problem or opportunity exists. These students work independently on their projects, but do not have all the knowledge, skills and capability to complete the project and therefore have to engage with a range of stakeholders which also proves a 
challenge for some students. Additionally, given the contemporary nature the future of work, and fast pace of change that is not always captured in academic research or published reports, there is often a need for students to speak with subject matter experts early in the development of their project proposals, as well as during the development of their solution. Students will benefit from a framework that helps them to manage these multiple tasks and workflows, as well as thinking critically about what they are reading, hearing, and writing. The fast-paced nature of technological development, and a wide range of EDTs that can often be used during the development of product prototypes also poses challenges. The iterative nature of the Scrum Cycle provides a framework for students to manage the development and testing of their product with the diverse range of stakeholders involved in projects.

\section{Scenario 2: Undergraduate Degree in Computing}

The second scenario focuses on the adoption of this model within an undergraduate course focusing on applying User Experience (UX) design concepts within the development of an artifact for a real company.

Formal research is not typically undertaken within an undergraduate program, however, many formal research concepts are used to ensure the output is appropriate and meets the users' requirement. Therefore, many research concepts are adopted within this course, including for user requirement elicitation, contextual inquiry and user testing. Since students are not typically exposed to formal research concepts within an undergraduate program our proposed model provides a more structured approach for scaffolding students. Scaffolding is also supported by undertaking most of the activities in a team. This team approach more fully aligns to the original concept of agile development as well as to Amiel and Reeves' (2008) analysis of design-based research and educational technology. Backlogs are, therefore, a vital part of the project, where they are used to manage teams and provide students' with accountability for tasks within the project.

This model also provides a more formalized approach for integrating many of the UX approaches. Since UX has no one model, it can often be confusing to navigate. However, the application of the integrated model provides a way for students to step through the different techniques and processes adopted within the UX discipline. For example, students build awareness and understanding of environmental needs, drawing from both user-centered and Design Thinking approaches, by adopting techniques such as contextual inquiry and competitor analysis. These approaches provide students with a clear understanding of their client/users' needs and situate their project within the wider environment. From this, students can design objectives for their product. The role of the framework is to keep students aware of the need to integrate their design tasks with both empathetic customer interactions and a focus on the contribution to learning above and beyond the digital artifact. The integration of the Scrum cycle provides a clear way for users to test assumptions and designs with users. The iteration of design provides both the opportunity for the evolution of the designs (from paper sketch to a high-fidelity prototype) but also the refinement and testing of designs drawing on both user and expert testing. Overall, the formalized nature of the proposed integrated model provides a structured approach to draw in concepts fundamental to UX, but also those of formal research and artifact development. 
Integrating Scrum With Other Design Approaches to Support Student Innovation Projects

\section{CONCLUSION}

The work presented in this chapter is a Scrum-based research framework for innovation-based student projects that has been developed within two specific contexts, based on observations of the difficulties that students face in completing innovative technology-based projects. The framework has been developed from a synthesis of various related models from the literature, along with reflections on how a Scrum-based approach has operated thus far in the programs discussed. It has been designed to support students in their research who have been given a grounding in several process models including Scrum and design thinking. So far, development of the framework has been driven by staff observations of how effectively students have been able to adopt a Scrum-based approach to their projects, and student activities within Scrum workshops, as the team has experimented with different ideas about how to give students suitable structural guidance in the management and completion of their projects. The intent is to integrate this into a student research guide. No empirical data collection has yet taken place and future research is needed to explore how this approach can improve project outcomes for students. The next stage of this work will be to gather some formal research data to refine the framework as students use it for their innovation-based projects.

\section{REFERENCES}

Amiel, T., \& Reeves, T. C. (2008). Design-based research and educational technology: Rethinking technology and the research agenda. Journal of Educational Technology \& Society, 11(4), 29-40.

Bai, X., Li, M., Pei, D., Li, S., \& Ye, D. (2018, May). Continuous delivery of personalized assessment and feedback in agile software engineering projects. In Proceedings of the 40th International Conference on Software Engineering: Software Engineering Education and Training (pp. 58-67). $10.1145 / 3183377.3183387$

Beck, K. (2001). Manifesto for Agile Software Development. https://agilemanifesto.org/

Brown, A. L. (1992). Design experiments: Theoretical and methodological challenges in creating complex interventions in classroom settings. Journal of the Learning Sciences, 2(2), 141-178. doi:10.120715327809j1s0202_2

Cobb, P., Confrey, J., diSess, A., Lehrer, R., \& Schauble, L. (2003). Design Experiments in Educational Research. Educational Researcher, 32(1), 9-13. doi:10.3102/0013189X032001009

Cockburn, A. (2008). Crystal Methodologies. http://alistair.cockburn.us/

Collins, A. (1992). Towards a design science of education. In E. Scanlon \& T. O'Shea (Eds.), New Directions in Educational Technology. Springer Science \& Business Media. doi:10.1007/978-3-642-77750-9_2

Conboy, K., Gleasure, R., \& Cullina, E. (2015). Agile Design Science Research. In B. Donnellan, M. Helfert, J. Kenneally, D. VanderMeer, M. Rothenberger, \& R. Winter (Eds.), New Horizons in Design Science: Broadening the Research Agenda. LNCS. 9073 (pp. 168-180). Springer. 
Integrating Scrum With Other Design Approaches to Support Student Innovation Projects

Gurusamy, K., Srinivasaraghavan, N., \& Adikari, S. (2016). An Integrated Framework for Design Thinking and Agile Methods for Digital Transformation. In A. Marcus (Ed.), Design, User Experience, and Usability: Design Thinking and Methods. LNCS 9746 (pp. 34-42). Springer., doi:10.1007/978-3319-40409-7_4

Hevner, A. R., March, S. T., Park, J., \& Ram, S. (2004). Design Science in Information Systems Research. Management Information Systems Quarterly, 28(1), 75-105. doi:10.2307/25148625

IBM. (2018). Agile, meet design thinking. https://www.ibm.com/downloads/cas/7KL6JLMJ

Keijzer-Broers, W., \& de Reuver, M. (2016). Applying Agile Design Sprint Methods in Action Design Research: Prototyping a Health and Wellbeing Platform (Vol. 9661). Springer.

Kelly, A. (2004). Design Research in Education: Yes, but is it Methodological? Journal of the Learning Sciences, 13(1), 115-128. doi:10.120715327809jls1301_6

Kimbell, L. (2011). Rethinking design thinking: Part I. Design and Culture, 3(3), 285-306. doi:10.27 52/175470811X13071166525216

Koh, J. H. L., Chai, C. S., Wong, B., \& Hong, H. Y. (2015). Design Thinking for Education: Conceptions and applications in teaching and learning. Springer.

March, S. T., \& Storey, V. C. (2008). Design science in the information systems discipline: An introduction to the special issue on design science research. Management Information Systems Quarterly, 32(4), 725-730. doi:10.2307/25148869

McKenney, S., \& Reeves, T. C. (2014). Educational design research. In Handbook of research on educational communications and technology (pp. 131-140). Springer. doi:10.1007/978-1-4614-3185-5_11

Melles, G., Anderson, N., Barrett, T., \& Thompson-Whiteside, S. (2015). Problem Finding through Design Thinking in Education. In P. Blessinger \& J.M. Carfora (Eds.), Inquiry-Based Learning for Multidisciplinary Programs: A Conceptual and Practical Resource for Educators (Innovations in Higher Education Teaching and Learning, Volume 3) (pp.191-209). Bingley, UK: Emerald. doi:10.1108/S2055364120150000003027

Norman, J. (2001). Design as a Framework for Innovative Thinking and Learning: How Can Design Thinking Reform Education? In E. Norman \& P. Roberts (Eds.), Design and technology educational research and curriculum development: The emerging international research agenda (pp. 90-100). Loughborough University.

Peffers, K., Tuunanen, T., Rothenberger, M. A., \& Chatterjee, S. (2007). A Design Science Research Methodology for Information Systems Research. Journal of Management Information Systems, 24(3), 45-77. doi:10.2753/MIS0742-1222240302

Peters, M. J., Howard, K., \& Sharp, M. J. A. (2012). The management of a student research project. Gower Publishing, Ltd.

Razzouk, R., \& Shute, V. (2012). What Is Design Thinking and Why Is It Important? Review of Educational Research, 82(3), 330-348. doi:10.3102/0034654312457429 
Romme, A. G. L. (2004). Action research, emancipation and design thinking. Journal of Community \& Applied Social Psychology, 14(6), 495-499. doi:10.1002/casp.794

Royce, W. (1970, August). Managing the Development of Large Software Systems. Paper presented at Technical Papers of Western Electronic Show and Convention (WesCon), Los Angeles, CA.

Schwaber, K., \& Sutherland, J. (2017). The Scrum Guide. https://Scrumguides.org/docs/Scrumguide/ v2017/2017-Scrum-Guide-US.pdf

Stanford. (2019). Stanford d.school. https://dschool.stanford.edu/

Takeda, H., Veerkamp, P., Tomiyama, T., \& Yoshikawa, H. (1997). Modeling Design Processes. AI Magazine, 11(4), 37-48.

Takeuchi, H., \& Nonaka, I. (1986, Jan.). The New New Product Development Game. Harvard Business Review, 137-146.

Vaishnavi, V., \& Kuechler, W. (2011). Promoting Relevance in IS Research: An Informing System for Design Science Research. Informing Science: The International Journal of an Emerging Transdiscipline, 14, 125-138. doi:10.28945/1498

Van Den Akker, J., Gravemeijer, K., McKenney, S., \& Nieveen, N. (Eds.). (2006). Educational Design Research. Routledge. doi:10.4324/9780203088364 